\title{
Üniversite Öğrencilerinin Yeme Davranışı Bozukluğuna Yatkınlıkları: Bitlis Eren Üniversitesi Örneği
}

\author{
Seda OĞUR ${ }^{* 1}$, Aziz AKSOY ${ }^{2}$, Halime SELEN ${ }^{2 *}$ \\ ${ }^{1}$ Bitlis Eren Üniversitesi, Gıda Mühendisliği Bölümü, Bitlis \\ ${ }^{21}$ Bitlis Eren Üniversitesi, Sağlık Yüksek Okulu Beslenme ve Diyetetik Bölümü, Bitlis
}

\begin{abstract}
Özet
Bu çalışmada Bitlis Eren Üniversitesi'nde öğrenim gören 294 üniversite öğrencisinin yeme davranışı bozukluğuna yatkınlıklarının belirlenmesi amaçlanmıştır. Öğrencilere cinsiyet, yaş, vücut ağırlığı ve boy uzunluğu bilgileri sorulup, Savaşır ve Erol (1989) tarafindan Türkçeye uyarlanan 40 soruluk Yeme Tutum Testi (YTT-40) uygulanmıştır. YTT-40'ın değerlendirme ölçeğine göre; “ $\geq 30$ ” puan alan kişiler "yeme davranışı bozukluğuna yatkın" şeklinde nitelendirilmiştir. Elde edilen veriler IBM SPSS $20 ®$ programında, sıklık ve Pearson ki-kare testleriyle değerlendirilmiştir. Kız öğrencilerin \% 11.9'unun ( $\mathrm{n}=21)$, erkek öğrencilerin \%14.9'unun ( $\mathrm{n}=18)$ YTT40 puanı $\geq 30$ olarak tespit edilmiştir. YTT-40 puanlarına göre; zayıf öğrencilerin $\% 7.8$ 'inin $(\mathrm{n}=3)$, normal öğrencilerin \%13.6'sının ( $\mathrm{n}=31)$ ve şişmanlık öncesi (pre-obez) öğrencilerin \%15.5'inin $(\mathrm{n}=5)$ yeme davranış1 bozukluğuna yatkın oldukları belirlenmiştir. Öğrencilerin yaş aralıklarına göre YTT-40 puanları değerlendirildiğinde; 17-23 yaş aralığındaki öğrencilerden \%13.8'inin $(n=38)$ ve 24-29 yaş aralığındaki öğrencilerden ise \%4.3'ünün $(\mathrm{n}=1)$ yeme davranışı bozukluğuna yatkın oldukları görülmüştür. Öğrencilerin ortalama YTT-40 puanları 18.14 \pm 9.95 olarak bulunurken; \%13.3'ünün $(n=39)$ yeme davranışı bozukluğuna yatkın olduğu belirlenmiştir. Ancak, öğrencilerin cinsiyetleri, BKİ değerleri ve yaş aralıkları ile YTT-40 puanları arasındaki farkın anlamlı olmadığı $(\mathrm{p}>0.05)$ ortaya çıkmıştır.
\end{abstract}

Anahtar Kelimeler: Yeme davranışı bozukluğu, yatkınlık, yeme tutumu, YTT-40, üniversite öğrencileri.

\section{Predispositions of University Students to Eating Behavior Disorder: Sample of Bitlis Eren University}

\begin{abstract}
In this study, it was aimed to determine that 294 students, studying at Bitlis Eren University, have a predisposition to eating behavior disorder. Gender, age, weight and height information has been asked and applied the 40-item Eating Attitudes Test (EAT-40), adapted to Turkish by Savaşır and Erol (1989). According to the EAT-40 evaluation scale; who score is " $\geq 30$ ", he is described as "he has a predisposition to eating behavior disorder". The data were evaluated in IBM SPSS $20 \AA$ program by frequency and Pearson chi-square tests. EAT-40 score was determined as $\geq 30$ in $11.9 \%(n=21)$ of girl students and in $14.9 \%(n=18)$ of men students. According to the EAT40 score, $7.8 \%(n=3)$ of weak students, $13.6 \%(n=31)$ of normal students and $15.5 \%(n=5)$ of before obesity (preobese) students had a predisposition to eating behavior disorder was specified. When EAT-40 score was evaluated according the age range of the students, it was seen that $13.8 \%(n=38)$ of students in the $17-23$ age range and $4.3 \%$ $(n=1)$ of students in the 24-29 age range had a predisposition to eating behavior disorder. Average EAT-40 score of the students was found as $18.14 \pm 9.95$ and $13.3 \%(n=39)$ of them had a predisposition to eating disorder was determined. But an insignificant difference $(\mathrm{p}>0.05)$ was emerged between gender and EAT-score, BMI value and EAT-score and age range and EAT-score.
\end{abstract}

Keywords: Eating behavior disorder, predisposition, eating attitude, EAT-40, university students.

\footnotetext{
* Sorumlu Yazar: sdogur@beu.edu.tr

Geliş Tarihi: 08.07.2015, Kabul Tarihi:11.03.2016
} 


\section{Giriș}

Yeme bozuklukları daha çok genç kız ve kadınları etkileyen ve günümüzde çok yaygın olarak rastlanan psikiyatrik bir hastalık olarak değerlendirilmektedir. Genellikle orta sosyo-ekonomik düzeyde, beyaz 1rkta ve çekiciliğin zayıflıkla bağlantılı olduğu kabul edilen endüstrileşmiş toplumlarda görülmektedir [1]. Yeme bozuklukları vakalarının \%90'dan fazlasını, 25 yaş altı bireyler oluşturmakta, kadınlarda erkeklere göre 5-20 kat görülmekte ve tüm vakaların sadece \%5-10'unu erkekler oluşturmaktadır [2]. Yeme bozuklukları beslenme yetersizliği, aşırı beslenme, depresyon, madde bağımlılı̆̆ı, anksiyete gibi ciddi sorunlara neden olabilen, yeme alışkanlıklarındaki sapmalardır [3].

Mental Bozuklukların Tanısal ve İstatistiksel El Kitabı-IV (DSM-IV) sınıflandırmasında, tanımlanmış (örn., anoreksiya nervoza, bulimiya nervoza ve tıkınırcasına yeme bozukluğu) ve sınıflandırılamayan diğer yeme davranışı bozuklukları (örn., ortoreksiya nervoza, diyabulimiya, gece yeme sendromu ve diğ.) yer almaktadır. Sınıflandırılamayan diğer yeme davranışı bozuklukları anoreksiya nervoza ve bulimiya nervoza dışındaki tüm yeme sorunlarını kapsamakta fakat anoreksiya nervoza ve bulimiya nervoza gibi özel tanımlamaları bulunmamaktadır [4].

Yeme bozuklukları hem bedensel hem de psikososyal boyutu olan; kişinin yemek, vücut ağırlı̆̆ ve fiziksel görüntüsü ile ilgili düşünce ve yeme davranışında bozuklukla kendini gösteren bir durumdur [5]. Yeme bozukluğu olan kişiler bedenini olduğundan şişman ve şekilsiz bulma, çok kısıtlı gıda alma, yemekleri takiben kusma veya kendini kusturma, laksatif kullanma ve aşırı egzersiz yapma gibi belirtiler sergileyebilirler [6]. Kadınlar, erkeklere göre, ince beden imgesine sahip olma ve diyet yapmayla belirgin düzeyde daha fazla ilgilidir ve bunların sonucunda da yeme bozukluğu riskine daha yatkındırlar. Yeme bozuklukları riskinin, özellikle belirli bir kiloda kalmaya dikkat etmeleri gereken mankenler, dansçılar ve jimnastikçiler arasında daha fazla olduğu görülmektedir [7].

Yeme bozukluğu için özgün bir neden ve patogenez bilinmemekle birlikte, risk etmenleri arasında genel, sosyal, ailesel, gelişimsel, psikolojik, davranışsal ve biyolojik etmenler ile yaşam olaylarının yer aldığı kabul edilmektedir [8]. Beden memnuniyetsizliği, ağırlık endişesi, erken matürasyon, düşük benlik saygısı, kusursuz olma arzusu ve karşı cinsle arkadaşlığa başlama en temel bireysel faktörler olarak sayılmaktadır $[9,10]$. Beden imajı ile yeme davranış bozukluklarının ilişkili olduğu bildirilmiştir [11]. Sosyo-kültürel faktörlerin, yeme bozuklukları gelişiminde etkili olduğu bilinmekte, toplumun zayıflığa önem vermesi, aileden, arkadaşlardan ve kitle iletişim araçlarından gelen baskılar yeme bozukluklarının gelişiminde önemli bir rol oynamaktadır [12].

İnsidansında 1980'lerden itibaren belirgin bir artışın da [13] gözlendiği yeme bozuklukları, ergenlerde ve genç erişkinlerdeki yüksek prevalansı, diğer ruhsal ve bedensel sorunlarla komorbidite ve mortalitesi nedeniyle erken tanı ve tedaviyi gerektiren bir durumdur [3, 14-17]. Yeme bozukluklarının klinik örneklem ve toplum içinde görülme yaygınlığı açısından farklılıklar bulunmaktadır [18, 19]. Farklı toplumlarda farklı yaygınlık oranlarının görüldüğü bildirilmekte ve özellikle batı toplumları ile doğu toplumları arasında görülme yaygınlığı açısından farklar olduğu bildirilmektedir [19, 20]. Amerika Psikoloji Derneği (APA)'ne [21] göre yeme bozukluklarının genel toplumdaki yaygınlığ $1 \% 0.5-\% 3$ arasındadır. Herhangi bir yeme bozukluğunun ergen ve genç erişkinlerde görülme sıklığı ise \%4 olarak bildirilmektedir [22]. Çeşitli yazarlar, yeme bozukluklarında değişen kültürel değer ve tutumların önemini vurgulamaktadır. Gelişiminde kültürün önemli rol oynadığı tek psikopatolojik tablonun, yeme bozuklukları olduğu öne sürülmüştür [23].

Gençlik dönemi, yaşam boyu devam eden alışkanlıkların yerleştiği bir dönemdir. Sağlıksız yeme tutumu da bu dönemde görülen riskli davranışlardandır [24, 25]. Gençlerin yeme tutumları birçok faktörden etkilenebilmektedir. Onların bu konudaki kendi bedenleri ile ilgili düşünceleri, algıları, genetik faktörleri, yaşam tarzları, alışkanlıkları vb. kişilerin sağlıklı ve sağlıssız davranışı seçmelerini etkileyen faktörlerdendir [26]. Yeme tutumları bir gereksinim olmaktan çok geleneklerle biçimlenmeye başlamakta ve dengesiz yeme alışkanlığı, bilinçsiz beslenme, yemek sırasında dikkat dağılması, 
zamansızlığı bahane edip yemek yemenin geçiştirilmesi ve hızlı yemek yeme gibi yeni alışkanlıklara dönüşmekte ve bu durum yeme bozukluklarına sebep olmaktadır [27]. Gençlerde yaygınlığı ve sıklığ1 giderek artan yeme bozuklukları Dünya Sağlık Örgütü tarafından "tıbbi dikkat” gerektiren "önemli tıbbi durum" olarak tanımlanmaktadır [14]. Yeme bozukluğu açısından yüksek riskli grupları en iyi temsil edenler lise ve üniversite öğrencileridir [20]. Yüksekokul öğrencisi kızların \%4-\%22'sinin anorektik ya da bulimik davranışlara girdiği bildirilmektedir [28-30].

- Yeme bozukluğu olan bireylerin yaygınlığına karşllık sağlık sistemi içinde yeterince tanınmadığı ve hastaların da bu konuda çare arayarak hekimleri yeterince uyarmadıkları bilinen bir gerçektir [31]. Hatta bu hastalar ayaktan hasta birimlerine başvursalar bile, onlardaki yeme sorunlarının sorgulanarak açığa çıkarılması pek olası olmamaktadır [32]. Oysa klinik görüşmede saptanamayan yeme bozukluklarını hastalar özbildirim ölçeklerinde daha rahat biçimde belirtebilmektedirler [33].

Yeme bozukluğunun üniversite öğrencilerindeki sıklığının saptanmasının koruyucu önlemlerin alınmasına katkı sağlayacağı düşünülmektedir. Çünkü üniversite öğrencileri gerek içinde bulundukları yaş, gerekse muhtemel psiko-sosyal ve ekonomik zorlanmalar nedeniyle yeme bozuklukları için risk grubunu oluşturmaktadır [34]. Üniversiteye başlayan pek çok genç şehir değişikliği, maddi durumun elverişsizliği, bağımsız yaşam arzusu gibi nedenlerle ailesinden ve evinden ayrılmaktadır. Tek başına ya da arkadaşlarıyla öğrenci yurtlarında, apartman dairelerinde, başka ailelerin yanlarında yaşamak gençlerin yaşam biçimlerinde önemli değişikliklere yol açmaktadır. Bu yüzden de özellikle üniversite öğrencileri arasında yeme bozukluklarının artış gösterdiği gözlemlenmektedir [35].

Bu kapsamda Bitlis Eren Üniversitesi’nde öğrenim gören öğrencilerin YTT-40 ölçeği ile yeme davranışı bozukluğuna yatkınlıklarının cinsiyet, yaş ve Beden Kütle İndeksi (BKİ) değişkenlerine göre belirlenmesi amaçlanmıştır.

\section{Gereç ve Yöntem}

Kesitsel araştırma olarak planlanan çalı̧̧mada Bitlis Eren Üniversitesi Etik Kurul Başkanlığı'ndan alınan izin sonrasında, 2014 yılı Aralık ayında, çalışmanın evrenini oluşturan Bitlis Eren Üniversitesi'nden lisans ve ön lisans programlarında öğrenim gören ve araştırmaya katılmayı gönüllü olarak kabul eden öğrenciler içinden, tesadüfi örneklem yöntemi ile seçilen, 17-29 yaş arasındaki 294 öğrenci örneklem olarak alınmıştır.

Veri toplama aracı olarak; öğrencilerin yaş, cinsiyet gibi demografik özelliklerini ve boy uzunluğu ve vücut ağırlığını içeren antropometrik ölçüm bilgilerinin yer aldığı form ve Yeme Tutum Testi (YTT-40) kullanılmıştır. Yeme tutum testi yeme bozukluğu olan hastaların yemek yeme ile ilgili davranış ve tutumlarını; normal bireylerde var olan yeme davranışlarındaki olası bozuklukların belirtilerini değerlendirmektedir. Toplam puanın düzeyi; psikopatolojinin düzeyi ile doğrudan ilişkilidir. YTT klinik düzeyde bozuk "hasta" kabul edilebilecek bireyleri saptayabileceği gibi, kişinin bu bozukluğa ne kadar yatkın olduğunun da bir göstergesi olabilmektedir. Orjinal ölçek birçok çalışmada normal popülasyondaki normal yeme tutum ve davranışlarını saptamak için kullanılmıştır [36, 37].

Yeme Tutum Testi (YTT-40) 6 dereceli (Daima, Çok sık, Sık sık, Bazen, Nadiren, Hiçbir zaman) Likert tipi yanıtlanan 40 maddeden oluşan özbildirime dayalı bir ölçektir. On bir yaşından büyük kişilere uygulanabilen, yeme bozukluğu olan ergenleri belirlemek ve anoreksiya nervoza belirtilerini ölçmek amaciyla Garner ve Garfinkel [38] tarafindan geliştirilmiş, Türkiye'de bu ölçeğin Türkçeye uyarlanması Savaşır ve Erol [39] tarafından yapılmıştır. Kesme noktası 30 puandır. Maddelerden 1, 18, 19, 23, 27, 39 için bazen 1 puan, nadiren 2 puan ve hiçbir zaman 3 puan ve diğer seçenekler 0 puan olarak değerlendirilmektedir. Ölçeğin diğer maddeleri için ise daima 3 puan, çok s1k 2 puan ve sık sık 1 puan ve diğer seçenekler 0 puan olarak hesaplanmaktadır. Sonuçta ölçeğin her bir maddesinden alınan puanlar toplanarak ölçeğin toplam puanı elde edilmektedir. Yürütülen çalışmada YTT-40'ın 
değerlendirme ölçeğine göre; “ $\geq 30$ ” puan alan kişiler "yeme davranışı bozukluğuna yatkın” şeklinde nitelendirilmiştir.

YTT-40'ın Türkiye'de geçerlik ve güvenilirlik çalışması Savaşır ve Erol [39] tarafindan yapılmıştır. Savaşır ve Erol [39] bir ay aralıkla tekrarladıkları testin güvenilirlik katsayısını 0.65 olarak; Cronbach alfa ile hesaplanan iç tutarlılı̆̆ 0.70 olarak saptamışlardır. Ölçeğin faktör analizi yağ oluşumundaki anksiyete, diyet davranışı, sosyal stres ve zayıflık obsesyonunu içeren 4 tane yorumlanabilir faktörü ortaya çıkarmıştır. Batur [40]'un çalışmasında ise ölçeğin Cronbach alfa güvenilirlik katsayısı kız öğrencilerde 0.47-0.90, erkek öğrencilerde ise 0.34-0.80 arasında bulunmuştur.

Dünya Sağlık Örgütü'nün obezite sınıflandırması (<18.5: zayıf, 18.5-24.9: normal, 25.0-29.9: şişmanlık öncesi, 30.0-34.9: 1. derece obez, 35.0-39.9: 2. derece obez, $>40$ : morbid obez) esas alınarak [41]; katılımcıların öz bildirimleriyle elde edilen vücut ağırlı̆̆1 ve boy uzunluğu bilgilerinden "Vücut Ağırlığı/(Boy uzunluğu)2 (kg/m2)" formülü ile öğrencilerin BKİ değeri hesaplanmıştır.

Elde edilen veriler IBM SPSS $20 \AA$ programında, siklık ve Pearson ki-kare testleriyle değerlendirilmiş, $\mathrm{p}<0.05$ düzeyi istatistiki açıdan anlamlı kabul edilmiştir.

\section{Bulgular ve Tartışma}

Çalışmaya dahil edilen öğrencilerin \%59.2'si (n=174) kız öğrencilerden, \%40.8'i $(n=120)$ erkek öğrencilerden oluşmuştur (Çizelge 1). Öğrencilerin yaş ortalaması $20.67 \pm 2.00$, vücut ağırlığ ortalaması $60.92 \pm 10.30 \mathrm{~kg}$, boy uzunluğu ortalamas $168.38 \pm 8.04 \mathrm{~cm}$ ve YTT-40 puanı ortalaması $18.14 \pm 9.95$ olarak tespit edilmiştir.

Çizelge 1. Öğrencilerin cinsiyetlerine ve yaş aralıklarına göre BKİ değerleri dağılımı

\begin{tabular}{|c|c|c|c|c|c|c|c|}
\hline \multirow{3}{*}{$\begin{array}{l}\text { Cinsiyet-Yaş Aralı̆̆ı } \\
\text { Cinsiyet }\end{array}$} & \multicolumn{6}{|c|}{ BKi Değeri } & \multirow{3}{*}{ Ki-kare } \\
\hline & \multicolumn{2}{|c|}{$\begin{array}{l}<18.5 \\
\text { (zayıf) }\end{array}$} & \multicolumn{2}{|c|}{$\begin{array}{l}\text { 18.5-24.9 } \\
\text { (normal) }\end{array}$} & \multicolumn{2}{|c|}{$\begin{array}{l}25.0-29.9 \\
\text { (şişmanlık öncesi, pre- } \\
\text { obez) }\end{array}$} & \\
\hline & $\mathbf{n}$ & $\%$ & $\mathbf{n}$ & $\%$ & n & $\%$ & \\
\hline$K ı z$ (n=174-\%59.2) & 31 & 17.8 & 133 & 76.4 & 10 & 5.7 & \multirow{3}{*}{18.230} \\
\hline Erkek ( $n=120-\% 40.8)$ & 7 & 5.8 & 91 & 75.8 & 22 & 18.3 & \\
\hline $\begin{array}{l}\text { Toplam } \quad(n=294- \\
\text { \%100) }\end{array}$ & 38 & 12.9 & 224 & 76.2 & 32 & 10.9 & \\
\hline Yaş Aralığı & $n$ & $\%$ & $n$ & $\%$ & $n$ & $\%$ & \multirow{4}{*}{3.535} \\
\hline $17-23(n=271-\% 92.2)$ & 36 & 13.3 & 208 & 76.8 & 27 & 10.0 & \\
\hline $24-29(n=23-\% 7.8)$ & 2 & 8.7 & 16 & 69.6 & 5 & 21.7 & \\
\hline $\begin{array}{l}\text { Toplam } \quad(n=294- \\
\% 100)\end{array}$ & 38 & 12.9 & 224 & 76.2 & 32 & 10.9 & \\
\hline
\end{tabular}

BKİ değerlerine göre; kız öğrencilerden \%17.8'inin ( $\mathrm{n}=31)$ zayıf $(<18.5)$, \%76.4'ünün $(\mathrm{n}=133)$ normal (18.5-24.9) ve \%5.7'sinin ( $\mathrm{n}=10)$ şişmanlı öncesi (pre-obez) (25.0-29.9) olduğu tespit edilmiştir. Erkek öğrencilerden \%5.8' inin ( $n=7)$ zayıf, \% 75.8' inin ( $n=91)$ normal ve \%18.3'ünün ( $n=22)$ şişmanlık öncesi (pre-obez) olduğu belirlenmiştir. Sonuçlardan da anlaşılacağ cinsiyetleri ile BKİ değerleri arasındaki farkın anlamlı $(\mathrm{p}<0.05)$ olduğu bulunmuştur. Erkek öğrencilerde, şişmanlık öncesi (pre-obez) öğrencilerin sayısının kız öğrencilerden daha fazla, normal öğrenci sayısının ise kız öğrencilerden daha az olduğu görülmüştür (Çizelge 1). 
Siyez ve Uzbaş [42]'ın gençlerin \%19.8'inin zayıf olduğunu tespit ettikleri ve Ulaş vd. [43]'nin öğrencilerin \%14.6'sının şişmanlık öncesi ve şişman, \%13.2'sinin zayıf olduğunun saptandığ1 çalışmalarıyla yürütülen çalışmanın benzer olmadığı görülmüştür.

Öğrencilerin yaş aralıkları ile BKİ değerleri arasındaki farkın anlamlı olmadığı ( $\mathrm{p}>0.05)$ belirlenmiştir. Öğrencilerin \%92.2'si (n=271) 17-23 yaş aralığında yer almakta olup, bu yaş aralığındaki öğrencilerin \%76.8'inin $(\mathrm{n}=208)$ normal ağırlıkta olduğu anlaşılmıştır. 24-29 yaş aralığındaki öğrencilerin ise \%69.6'sının ( $\mathrm{n}=16$ ) normal ağılıkta olduğu tespit edilmiştir (Çizelge 1).

YTT-40 ölçeğinin değerlendirilmesine göre; öğrencilerin \%13.3'ünün ( $\mathrm{n}=39)$ puanının $\geq 30$ olduğu ve bu sebeple yeme davranışı bozukluğuna yatkınlıklarının olduğu ortaya çıkmıştır. Öğrencilerden \%9.3’ünün (n=27) YTT-40 puanı 30-40 arasında, \%3.7'sinin (n=12) YTT-40 puanı 41 46 arasında iken; 1 kişinin (\%0.3) YTT-40 puanı 75 olarak bulunmuştur (Çizelge 2).

Çizelge 2. Yeme davranışı bozukluğuna yatkınlığı olan öğrencilerin cinsiyetlerine göre YTT-40 puanları dağılımı

\begin{tabular}{|c|c|c|c|c|c|c|c|}
\hline \multirow{3}{*}{ YTT-40 Puanı } & \multicolumn{4}{|c|}{ Cinsiyet } & \multirow{2}{*}{\multicolumn{2}{|c|}{$\begin{array}{c}\text { Toplam } \\
(n=39)\end{array}$}} & \multirow{3}{*}{ Ki-kare } \\
\hline & \multicolumn{2}{|c|}{$K_{12}(n=21)$} & \multicolumn{2}{|c|}{ Erkek $(n=18)$} & & & \\
\hline & $\mathbf{n}$ & $\%$ & $\mathbf{n}$ & $\%$ & $\mathbf{n}$ & $\%$ & \\
\hline 30 & 2 & 1.1 & 1 & 0.8 & 3 & 1.0 & \multirow{17}{*}{45.690} \\
\hline 31 & 4 & 2.3 & - & - & 4 & 1.4 & \\
\hline 32 & - & - & 2 & 1.7 & 2 & 0.7 & \\
\hline 33 & 2 & 1.1 & - & - & 2 & 0.7 & \\
\hline 34 & 1 & 0.6 & 1 & 0.8 & 2 & 0.7 & \\
\hline 35 & 2 & 1.1 & 3 & 2.5 & 5 & 1.7 & \\
\hline 36 & 1 & 0.6 & 2 & 1.7 & 3 & 1.0 & \\
\hline 39 & 2 & 1.1 & 2 & 1.7 & 4 & 1.4 & \\
\hline 40 & 2 & 1.1 & - & - & 2 & 0.7 & \\
\hline 41 & - & - & 3 & 2.5 & 3 & 1.0 & \\
\hline 42 & 1 & 0.6 & 1 & 0.8 & 2 & 0.7 & \\
\hline 43 & - & - & 1 & 0.8 & 1 & 0.3 & \\
\hline 44 & 2 & 1.1 & - & - & 2 & 0.7 & \\
\hline 45 & 1 & 0.6 & - & - & 1 & 0.3 & \\
\hline 46 & 1 & 0.6 & 1 & 0.8 & 2 & 0.7 & \\
\hline 75 & - & - & 1 & 0.8 & 1 & 0.3 & \\
\hline YTT-40 Puanı Ortalaması & \multicolumn{2}{|c|}{$18.35 \pm 8.78$} & \multicolumn{2}{|c|}{$17.83 \pm 11.48$} & \multicolumn{2}{|c|}{$18.14 \pm 9.95$} & \\
\hline
\end{tabular}

YTT-40 ile yapılan çalışmalarda 30 ve üzerinde puan alanların yalnızca \%7'sinin normal olduğu, geri kalan \%93'ünün yeme davranışı bozukluğu gösterdiği yayınlanmıştır [38].

Yürütülen çalışmada tespit edilen yeme davranışı bozukluğuna yatkınlığı olan öğrencilerin oranları (\%13.2) ile Ünalan vd. [34]'nin çalışmasındaki öğrencilerde yeme bozukluğu bulunma olasılığının (\%14) birbirine yakın olduğu görülmüştür. Ancak, Siyez ve Uzbaş [42]'ın yürüttüğü, öğrencilerin \%64'ünün $(\mathrm{n}=131)$ YTT-40 ölçeğinden 30 puanın üzerinde puan aldıkları çalışmanın sonuçları ve Uzun vd. [44]'nin öğrencilerin \%17'sinin YTT-40 ölçeğinden 30 puan ve üstü aldıkları çalışmanın sonuçları ile benzerlik taşımadığı belirlenmiştir.

Yürütülen çalışmada, Aslan ve Alparslan [45]'ın çalışmasında olduğu gibi, YTT-40 puan ortalaması kız öğrencilerde erkek öğrencilerden daha yüksek, yeme davranışı bozukluğuna yatkınlığı olan öğrencilerin oranı ise erkek öğrencilerde daha yüksek bulunmuştur. Öğrencilerin YTT-40 puanları ile cinsiyetleri arasındaki farkın anlamlı olmadığı (p>0.05) saptanmıştır. Kız öğrencilerde $18.35 \pm 8.78$ olan YTT-40 puan ortalamas1, erkek öğrencilerde 17.83 \pm 11.48 olarak bulunmuştur. Erol vd. [15]'nin

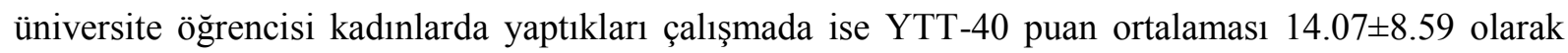
bulunmuştur.

Kı öğrencilerin \% 11.9'unun ( $\mathrm{n}=21)$, erkek öğrencilerin \%14.9'unun (n=18) YTT-40 puanı $\geq 30$ olarak tespit edilmiştir. En yüksek YTT-40 puanını (75) alan öğrencinin de erkek olduğu belirlenmiştir. YTT-40 ölçeğinden kız öğrencilerden \%09.0'u (16 kişi) 30-40 arasında, \%2.9’u (5 kişi) 41-46 arasında, erkek öğrencilerden ise \%8.2'si (n=11) 30-40 arasında, \%5.7'si (n=7) 41-46 arasında 
puan almıştır (Çizelge 2). Ancak, erkek öğrencilerde yeme davranışı bozukluğuna yatkınlığın daha yüksek olduğu anlaşıldığından; ayrıca öğrencilerin cinsiyetlerine göre "yeme davranışı bozukluğuna yatkınlığı var/yok" şeklinde ayrı bir değerlendirme daha yapıldığında aradaki farkın yine anlamlı olmadı ğı ( $\mathrm{p}>0.05)$ görülmüştür.

Smead ve Richert [28], Collins [47], Cantrell ve Ellis [48], Yeşilbursa vd. [49], İzmir vd. [50], Turnbull vd. [51], Wood vd. [52], Grange vd. [53], Erol vd. [54], Lindberg ve Hjern [55], Wang vd. [56], Siyez ve Uzbaş [42], Büyükgöze Kavas [57], Ünalan vd. [34], Keskin vd. [58], Ulaş vd. [43] ve Uskun ve Şabaplı [59] tarafından yapılan çalışmalarda kız öğrencilerin olası yeme bozukluğu bulunma riski oranlarının erkek öğrencilere göre anlamlı $(\mathrm{p}<0.05)$ düzeyde yüksek olduğunun belirlenmiş olması yürütülen çalışma ile örtüşmemektedir.

Bu çalışmada İlhan vd. [60]'nin yaptı̆̆ çalışmayla benzer şekilde yeme davranışı bozukluğuna yatkınlığı olan erkek öğrencilerin sayısının kız öğrencilerden daha yüksek olduğu, ancak YTT-40 puanları arasındaki farkın anlamlı olmadığı (p>0.05) görülmüştür. Siyez ve Uzbaş [42]'ın çalışmasında YTT-40 ölçeğinden kızların erkeklere göre iki kat daha fazla puan almasının yürütülen çalışma ile benzer olmadığı anlaşılmıştır.

Öğrencilerin yaş aralıkları ile YTT-40 puanları arasındaki farkın anlamlı olmadığ 1 (p>0.05) tespit edilmiştir. Ancak, 17-23 yaş aralığındaki öğrencilerden \%13.8'inin (n=38), 24-29 yaş aralığındaki öğrencilerden ise \%4.3'ünün ( $\mathrm{n}=1)$ yeme davranışı bozukluğuna yatkınlıklarının olduğu saptanmıştır (Çizelge 3).

Çizelge 3. Yeme davranışı bozukluğuna yatkınlığı olan öğrencilerin yaş aralıklarına göre YTT-40 puanları dağılımı

\begin{tabular}{|c|c|c|c|c|c|c|c|}
\hline \multirow{3}{*}{ YTT-40 Puanı } & \multicolumn{4}{|c|}{ Yaş Aralığı } & \multirow{2}{*}{\multicolumn{2}{|c|}{$\begin{array}{c}\text { Toplam } \\
(n=39)\end{array}$}} & \multirow{3}{*}{ Ki-kare } \\
\hline & \multicolumn{2}{|c|}{$17-23(n=38)$} & \multicolumn{2}{|c|}{$24-29(n=1)$} & & & \\
\hline & $\mathbf{n}$ & $\%$ & $\mathbf{n}$ & $\%$ & $\mathrm{n}$ & $\%$ & \\
\hline 30 & 3 & 1.1 & - & - & 3 & 1.0 & \multirow{16}{*}{29.171} \\
\hline 31 & 3 & 1.1 & 1 & 4.3 & 4 & 1.4 & \\
\hline 32 & 2 & 0.7 & - & - & 2 & 0.7 & \\
\hline 33 & 2 & 0.7 & - & - & 2 & 0.7 & \\
\hline 34 & 2 & 0.7 & - & - & 2 & 0.7 & \\
\hline 35 & 5 & 1.8 & - & - & 5 & 1.7 & \\
\hline 36 & 3 & 1.1 & - & - & 3 & 1.0 & \\
\hline 39 & 4 & 1.5 & - & - & 4 & 1.4 & \\
\hline 40 & 2 & 0.7 & - & - & 2 & 0.7 & \\
\hline 41 & 3 & 1.1 & - & - & 3 & 1.0 & \\
\hline 42 & 2 & 0.7 & - & - & 2 & 0.7 & \\
\hline 43 & 1 & 0.4 & - & - & 1 & 0.3 & \\
\hline 44 & 2 & 0.7 & - & - & 2 & 0.7 & \\
\hline 45 & 1 & 0.4 & - & - & 1 & 0.3 & \\
\hline 46 & 2 & 0.7 & - & - & 2 & 0.7 & \\
\hline 75 & 1 & 0.4 & - & - & 1 & 0.3 & \\
\hline
\end{tabular}

Yürütülen çalışmada öğrencilerin yaş aralıkları ile YTT-40 puanları arasındaki farkın anlamlı olmaması (p>0.05) Aslan ve Alparslan [45]'ın ve Ünalan vd. [34]'nin çalışması ile örtüşmektedir. Bulik [61] de anoreksiya nervozanın ergenlik öncesinde ya da orta ve üst yaşlarda başlama sıklığının arttığını gösteren bulgular elde etmiştir. Siyez ve Uzbaş [42]'ın araştırmasında ise yaş arttıkça yeme tutumu testinden alınan puan ortalamalarının azaldığı belirlenmiştir. Calam vd. [62] tarafından yapılan araştırmada da yaş ile yeme tutumları arasında anlamlı bir ilişki olduğu; özellikle 21-22 yaşlarındaki gençlerin 24-25 yaş grubundakilere göre yeme davranışıyla ilgili daha sık problem yaşadığı belirtilmektedir.Çizelge 3 'te de görüldüğü gibi yeme davranışı bozukluğuna yatkınlığı olan öğrencilerin oranı 17-23 yaş aralığındaki öğrencilerde daha yüksek bulunduğundan; öğrencilerin yaş aralıklarına göre "yeme davranışı bozukluğuna yatkınlığı var/yok" şeklinde ayrı bir değerlendirme daha yapıldığında aradaki farkın yine anlamlı olmadığı ( $>0.05)$ görülmüştür.

Öğrencilerin BKİ değerleri ile YTT-40 puanları arasındaki farkın anlamlı olmadığ $1(\mathrm{p}>0.05)$ belirlenmiştir. Zayıf öğrencilerin \% 7.8'inin ( $\mathrm{n}=3)$, normal öğrencilerin \%13.6'sının ( $\mathrm{n}=31)$ ve şişmanlık 
öncesi (pre-obez) öğrencilerin \%15.5'inin $(\mathrm{n}=5)$ yeme davranışı bozukluğuna yatkınlıklarının olduğu tespit edilmiştir. Zayıf öğrencilerin \%7.8'i $(n=3)$, normal öğrencilerin \%8.9'u $(n=20)$ ve şişmanlık öncesi (pre-obez) öğrencilerin \%12.4'ü $(n=4)$ 30-40 arasında; normal öğrencilerin \%0.4'ü (n=1) 75, normal öğrencilerin \%4.7'si (n=10) ve şişmanlık öncesi (pre-obez) öğrencilerin \%3.1'i $(n=1)$ 41-46 arasında puan almıştır (Çizelge 4).

Çizelge 4. Yeme davranışı bozukluğuna yatkınlığı olan öğrencilerin BKİ değerlerine göre YTT-40 puanları dağılımı

\begin{tabular}{|c|c|c|c|c|c|c|c|c|c|}
\hline \multirow{3}{*}{ YTT-40 Puanı } & \multicolumn{6}{|c|}{ BKi Değeri } & \multirow{2}{*}{\multicolumn{2}{|c|}{ Toplam (n=39) }} & \multirow{3}{*}{ Ki-kare } \\
\hline & \multicolumn{2}{|c|}{$\begin{array}{c}<18.5 \\
\text { (zayıf, } n=3)\end{array}$} & \multicolumn{2}{|c|}{$\begin{array}{c}\text { 18.5-24.9 (normal, } \\
n=31)\end{array}$} & \multicolumn{2}{|c|}{$\begin{array}{c}25-29.9 \\
\text { (şişmanlık öncesi, } \\
\text { pre-obez, } n=5 \text { ) }\end{array}$} & & & \\
\hline & $n$ & $\%$ & $\mathrm{n}$ & $\%$ & $n$ & $\%$ & $\mathrm{n}$ & $\%$ & \\
\hline 30 & - & - & 3 & 1.3 & - & - & 3 & 1.0 & \multirow{16}{*}{81.779} \\
\hline 31 & 1 & 2.6 & 3 & 1.3 & - & - & 4 & 1.4 & \\
\hline 32 & - & - & - & - & 2 & 6.2 & 2 & 0.7 & \\
\hline 33 & - & - & 2 & 0.9 & - & - & 2 & 0.7 & \\
\hline 34 & 1 & 2.6 & - & - & 1 & 3.1 & 2 & 0.7 & \\
\hline 35 & 1 & 2.6 & 4 & 1.8 & - & - & 5 & 1.7 & \\
\hline 36 & - & - & 2 & 0.9 & 1 & 3.1 & 3 & 1.0 & \\
\hline 39 & - & - & 4 & 1.8 & - & - & 4 & 1.4 & \\
\hline 40 & - & - & 2 & 0.9 & - & - & 2 & 0.7 & \\
\hline 41 & - & - & 3 & 1.3 & - & - & 3 & 1.0 & \\
\hline 42 & - & - & 1 & 0.4 & 1 & 3.1 & 2 & 0.7 & \\
\hline 43 & - & - & 1 & 0.4 & - & - & 1 & 0.3 & \\
\hline 44 & - & - & 2 & 0.9 & - & - & 2 & 0.7 & \\
\hline 45 & - & - & 1 & 0.4 & - & - & 1 & 0.3 & \\
\hline 46 & - & - & 2 & 0.9 & - & - & 2 & 0.7 & \\
\hline 75 & - & - & 1 & 0.4 & - & - & 1 & 0.3 & \\
\hline
\end{tabular}

Tekyaprak [63]'ın çalışmasında obez öğrencilerin YTT-40 puanlarının daha yüksek olduğu, Ünalan vd. [34]'nin çalışmasında ise normal kilolu öğrencilerde yeme bozukluğu bulunma oranlarının anlamlı düzeyde $(p<0.05)$ yüksek olduğu belirlenmiştir. Siyez ve Uzbaş [42]' in araştırmasında ise YTT40 puanı yüksek olanların normalden zayıf oldukları görülmüştür. Çizelge 4'te görüldüğg̈ gibi yeme davranışı bozukluğuna yatkınlığı olan öğrencilerin büyük çoğunluğunun, Ünalan vd. [34]'nin çalışmasıyla benzer şekilde, normal öğrencilerden oluştuğu ortaya çıkmıştır.

Yürütülen çalışmada öğrencilerin BKİ değerleri ile YTT-40 puanları arasındaki ilişkinin Coners vd. [64], Altuğ vd. [65], Erol vd. [15], Şengül ve Hekimoğlu [66], Moore ve Keek [67], Siyez ve Uzbaş [42], Ünalan vd. [34], Tekyaprak [63] ve Uskun ve Şabaplı [59]'nın çalışmalarından farklı olarak anlamlı olmadığı $(\mathrm{p}>0.05)$ tespit edilmiştir. Ancak, öğrencilerin BKİ değerleri ile YTT-40 puanları arasındaki farkın anlamlı olmamasının ( $\mathrm{p}>0.05)$ Aslan ve Alparslan [45]'ın, Tanrıverdi vd. [68]'nin lise öğrencilerindeki yeme bozukluğu olasılığını araştırdıkları çalışmalarıyla örtüştüğü görülmüştür.

$\mathrm{Bu}$ bulgu, şişmanlık ya da nesnel beden ağırlığının yeme davranışı bozukluklarıyla ilişkili olmadığını, yeme tutumu üzerinde kişinin kendi bedenini nasıl algıladığının rolünün olduğunu düşündürmektedir.Öğrencilerin YTT-40 ölçeğindeki ifadelere verdikleri yanıtların dağılımı Çizelge 5'ten görülmektedir. Öğrencilerden \%13.9'u $(\mathrm{n}=41)$ şişmanlamaktan ödünün koptuğunu, \%15.6's1 $(\mathrm{n}=46)$ acıktığında yemek yememeye çalıştığını, \%1.4'ü $(\mathrm{n}=4)$ yemek yedikten sonra kustuğunu, \%3.7'si ( $\mathrm{n}=11)$ yemek yedikten sonra aşırı suçluluk duygusu hissettiğini, \%6.8'i $(\mathrm{n}=20)$ tek düşüncesinin daha zayıf olmak olduğunu, \%1.7'si (n=5) günde birkaç kez tartıldığını, \%16.7'si (n=49) günlerce aynı yemeği yediğini, \%11.2'si $(n=33)$ şişmanlama düşüncesinin zihnini meşgul ettiğini, \%1.7'si $(n=5)$ kilo almamak için müshil kullandığını, \%10.9'ü $(n=32)$ yaşamını yiyeceğin kontrol ettiğini düşündüğünü, \%2.4'si $(n=7)$ perhiz yaptığını, \%4.1'ü $(n=12)$ midesinin boş olmasından hoşlandığını, \%3.1’ü (n=9) yemeklerden sonra içinden kusmak geldiğini ifade etmiştir (Çizelge 5). 
Çizelge 5. Öğrencilerin YTT-40 ölçeğindeki ifadelere verdikleri yanıtların dağılımı

\begin{tabular}{|c|c|c|c|c|c|c|c|c|c|c|c|c|}
\hline \multirow[t]{2}{*}{ ífadeler } & \multicolumn{2}{|c|}{ Daima } & \multicolumn{2}{|c|}{ Çok sık } & \multicolumn{2}{|c|}{ Sık sık } & \multicolumn{2}{|c|}{ Bazen } & \multicolumn{2}{|c|}{ Nadiren } & \multicolumn{2}{|c|}{$\begin{array}{l}\text { Hiçbir } \\
\text { zaman }\end{array}$} \\
\hline & $\mathbf{n}$ & $\%$ & $\mathbf{n}$ & $\%$ & $\mathbf{n}$ & $\%$ & $n$ & $\%$ & $\mathbf{n}$ & $\%$ & $\mathbf{n}$ & $\%$ \\
\hline $\begin{array}{l}\text { Başkalarıyla birlikte yemek yemekten } \\
\text { hoşlanırım, }\end{array}$ & 128 & 43.5 & 24 & 8.2 & 50 & 17.0 & 72 & 24.5 & 18 & 6.1 & 2 & 0.7 \\
\hline $\begin{array}{l}\text { Başkaları için yemek pişiririm, ama } \\
\text { pişirdiğim yemeği yemem, }\end{array}$ & 8 & 2.7 & 15 & 5.1 & 16 & 5.4 & 58 & 19.7 & 53 & 18.0 & 144 & 49.0 \\
\hline Yemekten önce sıkıntılı olurum, & 9 & 3.1 & 7 & 2.4 & 19 & 6.5 & 70 & 23.8 & 53 & 18.0 & 136 & 46.3 \\
\hline Şişmanlamaktan ödüm kopar, & 41 & 13.9 & 15 & 5.1 & 13 & 4.4 & 58 & 19.7 & 45 & 15.3 & 122 & 41.5 \\
\hline Acıktığımda yemek yememeğe çalışırım, & 46 & 15.6 & 12 & 4.1 & 21 & 7.1 & 43 & 14.6 & 33 & 11.2 & 139 & 47.3 \\
\hline Aklım fikrim yemektedir, & 26 & 8.8 & 9 & 3.1 & 12 & 4.1 & 47 & 16.0 & 80 & 27.2 & 120 & 40.8 \\
\hline $\begin{array}{l}\text { Yemek yemeği durduramadığım zamanlar } \\
\text { olur, }\end{array}$ & 21 & 7.1 & 13 & 4.4 & 16 & 5.4 & 86 & 29.3 & 58 & 19.7 & 100 & 34.0 \\
\hline Yiyeceğimi küçük küçük parçalara bölerim, & 45 & 15.3 & 19 & 6.5 & 44 & 15.0 & 75 & 25.5 & 64 & 21.8 & 47 & 16.0 \\
\hline Yediğim yiyeceğin kalorisini bilirim, & 8 & 2.7 & 6 & 2.0 & 14 & 4.8 & 58 & 19.7 & 63 & 21.4 & 145 & 49.3 \\
\hline $\begin{array}{l}\text { Ekmek, patates, pirinç gibi yüksek kalorili } \\
\text { yiyeceklerden kaçınırım, }\end{array}$ & 9 & 3.1 & 6 & 2.0 & 13 & 4.4 & 44 & 15.0 & 58 & 19.7 & 164 & 55.8 \\
\hline Yemeklerden sonra şişkinlik hissederim, & 42 & 14.3 & 28 & 9.5 & 40 & 13.6 & 97 & 33.0 & 52 & 17.7 & 35 & 11.9 \\
\hline Ailem fazla yememi bekler, & 75 & 25.5 & 21 & 7.1 & 48 & 16.3 & 52 & 17.7 & 32 & 10.9 & 66 & 22.4 \\
\hline Yemek yedikten sonra kusarım, & 4 & 1.4 & 1 & 0.3 & 5 & 1.7 & 17 & 5.8 & 35 & 11.9 & 232 & 78.9 \\
\hline $\begin{array}{l}\text { Yemek yedikten sonra aşırı suçluluk } \\
\text { duyarım, }\end{array}$ & 11 & 3.7 & 8 & 2.7 & 7 & 2.4 & 21 & 7.1 & 41 & 13.9 & 206 & 70.1 \\
\hline Tek düşüncem daha zayıf olmaktır, & 20 & 6.8 & 8 & 2.7 & 7 & 2.4 & 35 & 11.9 & 51 & 17.3 & 173 & 58,8 \\
\hline $\begin{array}{l}\text { Aldığım kalorileri yakmak için yorulana dek } \\
\text { egzersiz yaparım, }\end{array}$ & 10 & 3.4 & 4 & 1.4 & 6 & 2.0 & 39 & 13.3 & 74 & 25.2 & 161 & 54.8 \\
\hline Günde birkaç kere tartılırım, & 5 & 1.7 & 4 & 1.4 & 6 & 2.0 & 21 & 7.1 & 51 & 17.3 & 207 & 70.4 \\
\hline $\begin{array}{l}\text { Vücudumu saran dar elbiselerden } \\
\text { hoşlanırım, }\end{array}$ & 43 & 14.6 & 18 & 6.1 & 30 & 10.2 & 42 & 14.3 & 52 & 17.7 & 109 & 37.1 \\
\hline Et yemekten hoşlanırım, & 119 & 40.5 & 31 & 10.5 & 38 & 12.9 & 52 & 17.7 & 32 & 10.9 & 22 & 7.5 \\
\hline Sabahları erken uyanırım, & 17 & 5.8 & 9 & 3.1 & 24 & 8.2 & 72 & 24.5 & 75 & 25.5 & 97 & 33.0 \\
\hline Günlerce aynı yemeği yerim, & 49 & 16.7 & 25 & 8.5 & 38 & 12.9 & 82 & 27.9 & 50 & 17.0 & 50 & 17.0 \\
\hline $\begin{array}{l}\text { Egzersiz yaptığımda harcadığım kalorileri } \\
\text { hesaplarım, }\end{array}$ & 7 & 2.4 & 5 & 1.7 & 10 & 3.4 & 27 & 9.2 & 38 & 12.9 & 207 & 70.4 \\
\hline Adetlerim düzenlidir, & 42 & 14.3 & 29 & 9.9 & 24 & 8.2 & 37 & 12.6 & 26 & 8.8 & 16 & 5.4 \\
\hline Başkaları çok zayıf olduğumu düşünür, & 48 & 16.3 & 27 & 9.2 & 27 & 9.2 & 69 & 23.5 & 52 & 17.7 & 71 & 24.1 \\
\hline $\begin{array}{l}\text { Şimanlama (vücudumun yağ toplayacağı) } \\
\text { düşüncesi zihnimi meşgul eder, }\end{array}$ & 33 & 11.2 & 11 & 3.7 & 14 & 4.8 & 42 & 14.3 & 58 & 19.7 & 136 & 46.3 \\
\hline $\begin{array}{l}\text { Yemeklerimi yemek başkalarınınkinden } \\
\text { daha uzun sürer, }\end{array}$ & 37 & 12.6 & 27 & 9.2 & 27 & 9.2 & 74 & 25.2 & 68 & 23.1 & 61 & 20.7 \\
\hline Lokantada yemek yemeyi severim, & 49 & 16.7 & 34 & 11.6 & 36 & 12.2 & 84 & 28.6 & 61 & 20.7 & 30 & 10.2 \\
\hline Müshil kullanırım, & 5 & 1.7 & 5 & 1.7 & 5 & 1.7 & 10 & 3.4 & 17 & 5.8 & 252 & 85.7 \\
\hline Şekerli yiyeceklerden kaçınırım, & 14 & 4.8 & 11 & 3.7 & 14 & 4.8 & 66 & 22.4 & 85 & 28.9 & 104 & 35.4 \\
\hline Diyet (perhiz) yemekleri yerim, & 3 & 1.0 & 6 & 2.0 & 7 & 2.4 & 34 & 11.6 & 54 & 18.4 & 190 & 64.6 \\
\hline $\begin{array}{l}\text { Yaşamımı yiyeceğin kontrol ettiğini } \\
\text { düşünürüm, }\end{array}$ & 32 & 10.9 & 16 & 5.4 & 23 & 7.8 & 52 & 17.7 & 58 & 19.7 & 113 & 38.4 \\
\hline $\begin{array}{l}\text { Yiyecek konusunda kendimi } \\
\text { denetleyebilirim, }\end{array}$ & 50 & 17.0 & 30 & 10.2 & 45 & 15.3 & 70 & 23.8 & 47 & 16.0 & 52 & 17.7 \\
\hline $\begin{array}{l}\text { Yemek konusunda başkalarının bana baskı } \\
\text { yaptığını hissederim, }\end{array}$ & 25 & 8.5 & 10 & 3.4 & 23 & 7.8 & 50 & 17.0 & 46 & 15.6 & 140 & 47.6 \\
\hline $\begin{array}{l}\text { Yiyeceklerle ilgili düşünceler çok zamanımı } \\
\text { alır, }\end{array}$ & 13 & 4.4 & 5 & 1.7 & 18 & 6.1 & 42 & 14.3 & 68 & 23.1 & 148 & 50.3 \\
\hline Kabızlıktan yakınırım, & 27 & 9.2 & 10 & 3.4 & 19 & 6.5 & 47 & 16.0 & 49 & 16.7 & 142 & 48.3 \\
\hline Tatlı yedikten sonra rahatsız olurum, & 18 & 6.1 & 11 & 3.7 & 20 & 6.8 & 46 & 15.6 & 71 & 24.1 & 128 & 43.5 \\
\hline Perhiz yaparım, & 7 & 2.4 & 3 & 1.0 & 7 & 2.4 & 25 & 8.5 & 46 & 15.6 & 206 & 70.1 \\
\hline Midemin boş olmasından hoşlanırım, & 12 & 4.1 & 7 & 2.4 & 17 & 5.8 & 41 & 13.9 & 39 & 13.3 & 178 & 60.5 \\
\hline $\begin{array}{l}\text { Şekerli, yağlı yiyecekleri denemekten } \\
\text { hoşlanırım, }\end{array}$ & 50 & 17.0 & 28 & 9.5 & 29 & 9.9 & 54 & 18.4 & 65 & 22.1 & 68 & 23.1 \\
\hline Yemeklerden sonra içimden kusmak gelir & 9 & 3.1 & 3 & 1.0 & 9 & 3.1 & 14 & 4.8 & 44 & 15.0 & 215 & 73.1 \\
\hline
\end{tabular}

Benzer bir çalışmada, bu çalışmadan çok farklı olmayan tespitlere göre; yeme tutumları açısından bakıldığında öğrencilerin \%2'sinin $(n=4)$ düzenli olarak rejim yaptığı, \%7.4'ünün $(n=15)$ sürekli zayıf olmayı düşündüğü, \%6.9'unun (n=14) zaman zaman laksatif kullandığı ve \%3'ünün (n=6) 
yemeklerden sonra suçluluk duygusu hissettiği belirlenmiş, sadece 1 öğrenci yemeklerden sonra kustuğunu ifade etmiştir [42].

\section{4. Çalışmanın Güçlü Yönleri ve Sınırlılıkları}

Bu çalışma, YTT-40 ölçeğinin [38] kullanılması ile Bitlis Eren Üniversitesi öğrencilerinin bir kısmının yeme davranışı bozukluğuna yatkınlıklarını değerlendiren ilk çalışmadır. Ancak yeme davranışı bozukluğuna neden olabilecek; ailelerinin yeme tutumları, öğrencilerin sağlık veya hastalık durumları gibi bağımsız değişkenlerin yeme davranışı bozukluğunun gelişimi üzerindeki etkisinin değerlendirilmemesi ve kesin tanı için klinik ve psikolojik incelemelere de ihtiyaç olması sebebiyle çalışmaya dahil edilen öğrencilerin yeme davranışı bozukluğu taşıdıklarının tam olarak kabul edilmesi konusunda yetersiz kalmaktadır.

\section{Sonuç ve Öneriler}

Yeme davranışı bozukluğu ile ilgili eğitim ve önleyici tedbirlerin alınması, korunmanın sağlanması, şayet hastalık oluşmuşsa tedavinin sağlanması gerekmektedir. Tanı konmamış veya gizli kalmış subklinik yeme bozukluklarının; genç grupta geniş örneklemli, boylamsal çalışmalarla araştırılması, riskli gruplarda taramaların yapılması yararlı olacaktır.

Yeme davranışı bozukluğunun nedenlerinin belirlenmesi, koruyucu önlemler alınması ve bu hastalıkların tanınması açısından son derece önemlidir. Ayrıca gençlerin, ailelerin ve eğiticilerin konu ile ilgili olarak bilgilendirilmesi ve bilinçlendirilmesi için konferans ve seminer çalışmaları yapılmalıdır. Üniversite öğrencilerine sağlıklı beslenme alışkanlıklarının örgün ve yaygın eğitim kurumlarında verilen uygulamalı beslenme eğitimi ile kazandırılması ve bu sayede yaşam kalitelerinin arttırılması sağlanmalıdır•

\section{Teşekkür}

Araştırmanın verilerinin toplanmasında destek veren, Bitlis Eren Üniversitesi Sağlık Yüksekokulu Beslenme ve Diyetetik Bölümü öğrencilerinden Şeyda GÜNGÖR'e çalışmaya yapmış olduğu katkı ve emeği için çok teşekkür ederiz.

\section{Kaynaklar}

1. Houtkooper L. 2000. Clinical Sport Nutrition, in Eating Disorders and Disordered Eating in Athletes, Edited by Burke L. and Deaki V., New York: The McGraw-Hill Companies, 210-235.

2. Deering S. 2001. Eating Disorders: Recognition, Evaluation and Implications for Obstetrician/Gynecologists, Primary Care Update Obtetricians/Gynrcologists, 8 (1): 31-35.

3. Pritts S.D., Susman J. 2003. Diagnosis of Eating Disorders in Primary Care, American Family Physician, 67 (2): 297-304.

4. American Psychiatric Association (APA) 2013. Diagnostic and Statistical Manual of Mental Disorders, Fifth edition (DSM-5), Washington, DC.

5. Becker A.E., Grinspoon S.K., Klibanski A., Herzog D.B. 1999. Current Concepts: Eating Disorders, The New England Journal of Medicine, 340: 1092-1098.

6. Abraham S., Llewellyn-Jones D. 1997. Eating Disorders the Facts, 4th Edition, Oxford University Press, New York, 29-33.

7. Davison G.C., Neale J.M. 2004. Anormal Psikolojisi (Çev. Dağ İ.), Türk Psikologlar Derneği Yayınlar1, No: 29, 256s. İstanbul.

8. Ağırman A. Maner F. 2010. YB ve Duygusal İstismar: Olgu Sunumu, Düşünen Adam: Psikiyatri 
ve Nörolojik Bilimler Dergisi, 23: 121-127.

9. Güleç M., Yabancı N., Göçgeldi E., Bakır B. 2008. Ankara'da İki Kız Öğrenci Yurdunda Kalan Öğrencilerin Beslenme Alışkanlıkları, Gülhane Tıp Dergisi, 50 (2): 102-109.

10. Baş M. 2008. Yeme Bozukluklarında Diyetsel Yaklaşım ve Ağırlık Yönetimi İlişkisi, içinde Yetişkinlerde Ağırlık Yönetimi, Baysal A., Baş M. (Ed.), Birinci Basım, Ekspres Baskı, İstanbul, 202-234.

11. Thompson J.K., Coovert M.D., Richards J.K., Jhonson S., Cattarin J. 1995. Development of Body Image, Earing Disturbance and General Pschological Functioning in Female Adolescents: Covariance Structure Modeling and Longitudinal Investigations, International Journal of Eating Disorders, 18 (3): 221-236.

12. Satman İ., Yilmaz T., Sargin M. 2002. Population-Based Study of Diabetes and Risk Characteristics in Turkey, Diabetes Care, 25 (9): 1551-1556.

13. Granillo T., Jones-Rodriguez G., Carvajal S.C. 2005. Prevalence of Eating Disorders in Latina Adolescents: Associations with Substance Use and Other Correlates, Journal of Adolescent Health, 36 (3): 214-220.

14. Janout V., Janoutova G. 2004. Eating Disorders Risk Groups in the Czech Republic-CrossSectional Epidemiologic Pilot Study, Biomedical Papers, 148 (2): 189-193.

15. Erol A., Toprak G., Yazıcı F. 2002. Üniversite Öğrencisi Kadınlarda Yeme Bozukluğu ve Genel Psikolojik Belirtileri Yordayan Etkenler, Türk Psikiyatri Dergisi, 13 (1): 48-57.

16. Piran N. 1999. Eating Disorders: A Trial Prevention in a High Risk School Setting, The Journal of Primary Prevention, 20 (1): 75-90.

17. Bizeul C., Brun J.M., Rigaud D. 2003. Depression Influences the EDI Scores in Anorexia Nervosa Patients, European Psychiatry, 18 (3): 119-123.

18. Hoek H.W. 2002. Distrubition of Eating Disorders, in Eating Disorders and Obesity, Edited by Fairburn C.G., Brownell K.D., 2th Ed., Vol. 1, The Guilford Press, New York, 233-237.

19. Hoek H.W. 2006. Incidence, Prevalence and Mortality of Anorexia Nervosa and Other Eating Disorders, Current Opinion in Psychiatry, 19 (4): 389-394.

20. Van Hoeken D., Seidell J., Hoek H.W. 2003. Epidemiology, in Handbook of Eating Disorders, Edited by Treasure J., Schmidt, U., van Furth E., 2th Ed., John Wiley and Sons Ltd., England, 1134.

21. APA 1994. American Psychiatric Association, Diagnostic and Statistical Manual of Mental Disorders, 4th Ed., American Psychiatric Association Press, Washington DC.

22. Ertan T. 2008. Psikiyatrik Bozuklukların Epidemiyolojisi, Türkiye'de Sık Karşılaşılan Psikiyatrik Hastalıklar Sempozyum Dizisi, No: 62, s: 25-30.

23. Yates A. 1990. Current Perspectives on the Eating Disorders: II. Treatment, Outcome, and Research Directions, Journal of the American Academy of Child \& Adolescent Psychiatry, 29 (1): 1-9.

24. Kann L., Kinchen S.A., Williams B.I., Ross J.G., Lowry R., Kolbe L. 2000. Youth Risk Behavior Surveillance United States, Journal of School Health, 70 (7): 271-285.

25. Tezcan S., Aslan D., Esin A. Mutlu M.F., Nalbantoğlu B., Şenoğuz M. ve diğ. 2002. Ankara'da Bir İlköğretim Okulunda 6., 7. ve 8. Sınıf Öğrencilerinin Beslenme Alışkanlıklarının ve Durumunun Saptanması Araştırması, 8. National Public Health Congress, s.733-735, Diyarbakır.

26. Aslan D., Gürtan E., Hacım A., Karaca N., Şenol E., Yıldırım E. 2003. Ankara'da Eryaman Sağlık Ocağı Bölgesinde Bir Lisenin İkinci Sınıfında Okuyan Kız Öğrencilerin Beslenme Durumlarının ve Bazı Antropometrik Ölçümlerinin Değerlendirmeleri, Cumhuriyet Üniversitesi Tıp Fakultesi Dergisi, 25 (2): 55-62.

27. Kundakçı H. 2005. Üniversite Öğrencilerinin Yeme Tutumları, Benlik Algısı, Vücut Algısı ve Stres Belirtileri Açısından Karşılaştırılması, Ankara Üniversitesi, Sosyal Bilimler Enstitüsü, Psikoloji (Sosyal Psikoloji) Anabilim Dalı, Yüksek Lisans Tezi, 143s, Ankara. 
28. Collins M., Kriesberg J., Pertschuk M., Fager S. et al. 1982. Bulimia in College Women: Prevalence and Psychopathology, Journal of Adolescent Health Care, 3 (2): 144-158.

29. Pyle R.L., Neuman P.A., Halvorson P.A., Mitchell J.E. 1990. An Ongoing Cross-sectional Study of the Prevalence of Eating Disorders in Freshman College Students, International Journal of Eating Disorders, 10 (6): 667-677.

30. Thompson M.G., Schwartz D.M. 1982. Life Adjustment of Women with Anorexia Nervosa and Anorexic-like Behavior, International Journal of Eating Disorders, 1 (2): 47-60.

31. Hart L.M., Granillo M.T., Jorm A.F., Paxton S.J. 2011. Unmet Need for Treatment in the Eating Disorders: A Systematic Review of Eating Disorder Specific Treatment Seeking among Community Cases, Clinical Psychology Review, 31 (5): 727-735.

32. Hautala L., Junnila J., Alin J., Grönroos M., Maunula A.M., Karukivi M., Liuksila P.R., Räihä H., Välimäki M., Saarijärvi S. 2009. Uncovering Hidden Eating Disorders Using the SCOFF Questionnaire: Cross-sectional Survey of Adolescents and Comparison with Nurse Assessments, International Journal of Nursing Studies, 46 (11): 1439-1447.

33. Keel P.K., Crow S., Davis T.L., Mitchell J.E. 2002. Assessment of Eating Disorders: Comparison of Interview and Questionnaire Data from a Long-term Follow-up Study of Bulimia Nervosa, Journal of Psychosomatic Research, 53 (5): 1043-1047.

34. Ünalan D., Öztop D.B., Elmalı F., Öztürk A., Konak D., Pırlak B., Güneş D. 2009. Bir Grup Sağlık Yüksekokulu Öğrencisinin Yeme Tutumları ile Sağlıklı Yaşam Biçimi Davranışları Arasındaki İlişki, İnönü Üniversitesi Tıp Fakültesi Dergisi, 16 (2): 75-81.

35. Kazkondu İ. 2010. Üniversite Öğrencilerinde Ortoreksiya Nervoza (Sağlıklı Beslenme Takıntısı) Belirtilerinin İncelenmesi, Gazi Üniversitesi, Eğitim Bilimleri Enstitüsü, Aile Ekonomisi ve Beslenme Eğitimi Anabilim Dalı, Yüksek lisans tezi, 95s. Ankara.

36. Button E.J., Whitehouse A. 1981. Subclinical Anorexia Nervosa, Psychological Medicine, 11 (3): 509-510.

37. Patton G.C., Johnson-Sabire T., Wood K., Mann A.H., Wakeling A. 1990. Abnormal Eating Attitudes in London School Girls a Perspective Epidemiological Study: Outcome at Twelve Months Follow-up, Psychological Medicine, 20 (2): 383-394.

38. Garner D.M., Garfinkel P.E. 1979. The Eating Attitudes Test: An Index of the Symptoms of Anorexia Nervosa, Psychological Medicine, 9 (2): 273-279.

39. Savaşır I., Erol N. 1989. Yeme Tutum Testi: Anoreksi Nervoza Belirtileri İndeksi, Psikoloji Dergisi, 7(23): 19-25.

40. Batur S. 2004. Yeme Tutum Bozukluğu Gösterenlerde ve Göstermeyenlerde Temel Bilişsel Şemalar, Yayınlanmamış Doktora Tezi, Ankara Üniversitesi Sosyal Bilimler Enstitüsü, Ankara.

41. WHO 2006. BMI Classification. http://apps.who.int/bmi/index.jsp?introPage=intro 3.html. (Erişim Tarihi: 15.08.2015).

42. Siyez D.M., Uzbaş A. 2006. Bir Grup Üniversite Öğrencisinin Anoreksik Yeme Tutumları İle Aile Yapısı Arasındaki İlişki, New/Yeni Symposium Journal-www.yenisymposium.net, 44 (1): 37-43.

43. Ulaş B., Uncu F., Üner S. 2013. Sağlık Yüksekokulu Öğrencilerinde Olası Yeme Bozukluğu Siklığ1 ve Etkileyen Faktörler, İnönü Üniversitesi Sağlık Bilimleri Dergisi, 2: 15-22.

44. Uzun Ö., Güleç N., Özşahin A., Doruk A., Özdemir B., Çalışkan U. 2006. Screening Disordered Eating Attitudes and Eating Disorders in A Sample of Turkish Female College Students, Comprehensive Psychiatry, 47 (2): 123-126.

45. Aslan H. ve Alparslan N. 1998. Bir Grup Üniversite Öğrencisinde Yeme Tutumu İle Obsesif Kompulsif Belirtiler, Aleksitimi ve Cinsiyet Rolleri Arasındaki İlişki, Çocuk ve Gençlik Ruh Sağlığı Dergisi, 5(2): 61-69.

46. Smead V.S., Richert A.J. 1990. Eating Attitudes Test Factors in An Unselected Undergraduate Population, International Journal of Eating Disorders, 9 (2): 211-215. 
47. Collins M.E. 1991. Body Figure Perceptions and Preferences Among Preadolescent Children, International Journal of Eating Disorders, 10 (2): 199-208.

48. Cantrell P.J., Ellis J.B. 1991. Gender Role and Risk Patterns for Eating Disorders in Men and Women, Journal of Clinical Psychology, 47 (1): 53-57.

49. Yeşilbursa D., İmre HH., Türkcan S. ve diğ. 1992. Lise Öğrencilerinde Anoreksiya NervozaBulimia Nervoza, Nöropsikiyatri Arşivi, 29: 138-144.

50. İzmir M., Erman H., Canat S. 1994. Ankara'da Üç Değiş̧ik Okulda Uygulanan Yeme Tutumu Testi Sonuçlarının Değerlendirilmesi, Çocuk ve Gençlik Ruh Sağlığı Dergisi, 1(2): 70-74.

51. Turnbull S., Ward A., Treasure J., Jick H., Derby L. 1996. The Demand for Eating Disorder Care: An Epidemiological Study Using the General Practise Research Database, The British Journal of Psychiatry, 169 (6): 705-712.

52. Wood K.C., Becker J.A., Thompson J.K. 1996. Body Image Dissatisfaction in Preadolescent Children, Journal of Applied Developmental Psychology, 17 (1): 85-100.

53. Grange D., Telch C.F., Tibbs J. 1998. Eating Attitudes and Behaviors in 1435 South African Caucasian and Non-Caucasian College Students, The American Journal of Psychiatry, 155 (2): 250-254.

54. Erol A., Toprak G., Yazıc1 F., Erol S. 2000. Üniversite Öğrencilerinde Yeme Bozukluğu Belirtilerini Yordayıcı Olarak Kontrol Odağı ve Benlik Saygısının Karşılaştırılması, Klinik Psikiyatri, 3: 147-152.

55. Lindberg L., Hjern A. 2003. Risk Factors for Anorexia Nervosa: A National Cohort Study, Journal of Eating Disorders, 34 (4): 397-408.

56. Wang Z., Byrne N.M., Kenardy J.A., Hills A.P. 2005. Influences of Ethnicity and Socioeconomic Status on the Body Dissatisfaction and Eating Behaviour of Australian Children and Adolescents, Eating Behaviours, 6 (1): 23-33.

57. Büyükgöze Kavas A., 2007. Eating Attitudes and Depression in a Turksih Sample, European Eating Disorders Review, 15 (4): 305-310.

58. Keskin Y., Lüleci N.E., Çelik Ş., Erşan N., Dikyol M., Durucu B., Erşan T., Hekim O. 2010. Maltepe Üniversitesi Tıp Fakültesi Öğrencilerinde Olası Yeme Bozukluğu Sıklı̆ğ, Maltepe Tıp Dergisi, 2 (2):18-25.

59. Uskun E., Şabaplı A. 2013. Lise Öğrencilerinin Beden Algıları İle Yeme Tutumları Arasındaki İlişki, TAF Preventive Medicine Bulletin, 12 (5): 519-528.

60. İlhan M.N., Özkan S., Aksakal F.N., Aslan S., Durukan E., Maral I. 2006. Bir Tip Fakültesi Öğrencilerinde Olası Yeme Bozukluğu Sıklığı, Türkiye'de Psikiyatri, 8 (3): 151-155.

61. Bulik C.M. 2002. Eating Disorders in Adolescents and Young Adults, Child and Adolescent Psychiatric Clinics of North America, 11 (2): 201-218.

62. Calam R., Waller G., Slade P., Newton T. 1990. Eating Disorders and Perceived Relationships with Parents. International Journal of Eating Disorders, 9 (5):479-485.

63. Tekyaprak N. 2013. Correlation of Self-Esteem Eating Attitudes and Obesity Among Adolescents, Near East University Graduate School of Social Sciences Applied (Clinical) Psychology Master Program, Master thesis, 56s, North Cyprus.

64. Coners H., Remschmidt H., Hebebrand J. 1999. The Relationship Between Premorbid Body Weight, Weight Loss, and Weight at Referral in Adolescent Patients with Anorexia Nervosa, International Journal of Eating Disorders, 26 (2): 171-178.

65. Altuğ A., Elal G., Slade P., et al. 2000. The Eating Attitudes (EAT) in Turkish University Students: Relationship with Sociodemographic, Social and Individual Variables, Eating and Weight Disorders, 5 (3): 152-160.

66. Şengül A.M., Hekimoğlu Ş. 2005. Vücut Kitle İndeksi İle Yeme Tutumu Test Puanları Arasındaki İlişki, Göztepe Tıp Dergisi, 20 (1): 21-23. 
67. Moore F., Keek P.K. 2003. Influence of Sexual Orientation and Age on Disordered Eating Attitudes and Behaviors in Women, International Journal of Eating Disorders, 34 (3): 370-394.

68. Tanrıverdi D., Savaş E., Gönüllüoğlu N., Kurdal E., Balık G. 2011. Lise Öğrencilerinin Yeme Tutumları, Yeme Davranışları ve Benlik Saygılarının İncelenmesi, Gaziantep Tıp Dergisi, 17 (1): 33-39. 